\title{
Site performance of galvanic anodes in concrete repairs
}

\author{
C. Christodoulou \\ AECOM Europe, Colmore Plaza, 20 Colmore Circus Queensway, Birmingham, B4 6AT, UK, email to: \\ Christian.christodoulou@aecom.com \\ C.I. Goodier \& S.A. Austin \\ Loughborough University, School of Civil and Building Engineering, Loughborough, UK
}

\begin{abstract}
Galvanic anodes can be used to limit the extent of concrete replacement and extend the service life of patch repairs to reinforced concrete (RC) structures. They respond to changes in environmental conditions and this attribute has been employed to extend their use.

Traditionally, galvanic anodes are installed within the repair area itself. Although simple to install, this has certain limitations however, due primarily to the resistivity of the repair material. A recent alternative has been to install galvanic anodes in pre-drilled cavities in the parent concrete around the perimeter of the patch repair.

This paper reviews and compares the performance of discrete galvanic anodes installed both within the repair area and parent concrete in full-scale RC structures. Results indicate that galvanic anodes installed within the parent concrete had a more profound effect on the polarisation of the steel around the perimeter of the patch repair. This provides the empirical basis for alternative designs incorporating galvanic anodes that will enable increased corrosion protection to the steel reinforcement around the patch repair, which is generally considered to be at the highest risk.
\end{abstract}

\section{INTRODUCTION}

Patch repairs of deteriorating concrete is a common approach to rehabilitate defective concrete structures. Bridge Advice Note 35 (DMRB 1990) suggests that areas which show chloride concentrations greater than $0.3 \%$ by weight of cement and half-cell potential measurements higher than $-350 \mathrm{mV}$ should be removed. Concrete replacement to this extent on chloride-contaminated structures can be very onerous and expensive (Christodoulou 2008).

Galvanic anodes have been used to limit the extent of concrete replacement and extend the service life of patch repairs (NACE 2005, Concrete Society 2011, Christodoulou et al. 2011). They are based on the principle that different metals produce different potentials. Therefore, particular metals can be used which will corrode sacrificially to protect the steel reinforcement and offer protection. Their main advantage over other electrochemical treatments is the lack of need for a power supply and associated complex wiring installations. In addition, performance monitoring is straight forward and does not involve complex electronics. However, it is acknowledged that they have a lower protective current output and as a result might be ineffective in concrete with high corrosion rates (Christodoulou et al. 2009).

Galvanic anodes respond to changes in the environmental conditions that they are exposed to (John and Cottis 2003, NACE 2005, Christodoulou et al. 2009). Such an effect will be more dominant in parent concrete that has a residual level of chloride contamination as opposed to non-contaminated repair concrete or mortar and this has been employed to extend the use of galvanic anodes (Holmes et al. 2011, Glass et al. 2012).

The work presented here examined the performance of discrete galvanic anodes installed both within the parent concrete around the perimeter of the repair and also within the patch repair area itself.

\section{METHODOLOGY}

This section describes the full-scale RC structure that received patch repairs with galvanic anodes both within the patch repair itself and in the parent concrete around the patch repair, the properties of the galvanic anodes and the testing arrangement.

\subsection{Structure}

A multi-storey car park (MSCP) in the UK suffering from chloride-induced corrosion was selected for this work (Figure 1). The structure was built in the early 1970 s with one-way spanning concrete ribbed type deck arrangement. 


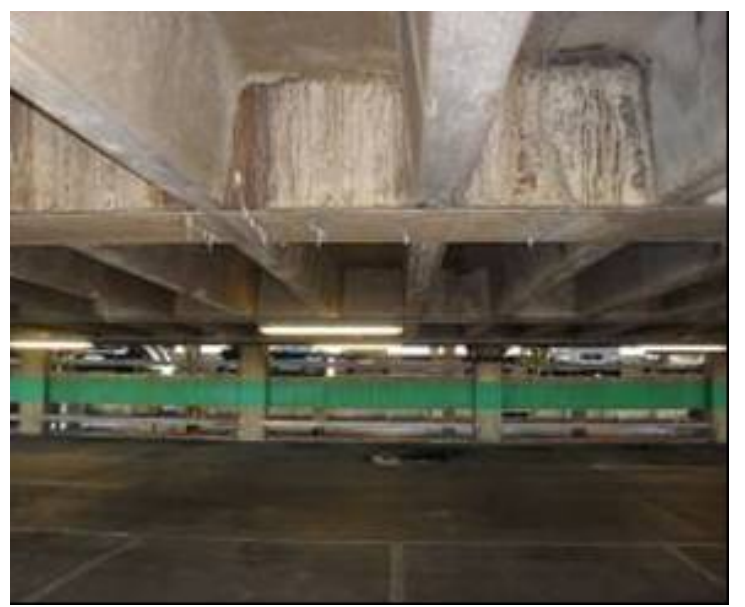

Figure 1. General condition of the MSCP's soffit indicating leaching, dynamic cracking and deterioration of the concrete elements.

Intrusive investigations were undertaken in 1997, 1999 and 2008 to determine the extent of chloride contamination whilst also assessing the probability of corrosion activity with potential mapping. The decks and soffits, especially adjacent to the expansion joints, appeared to have high levels of chloride concentration at the depth of reinforcement; hence according to Bridge Advice Note 35 (DMRB 1990) there was a significantly high risk of corrosion. By 2008, there were locations where the chloride levels were up to $2.9 \%$ by weight of cement at a depth of 30 to $55 \mathrm{~mm}$, where the reinforcement was located.

The profile of the chloride levels over a period of approximately 11 years suggested that chlorides were brought to the unprotected surface of the decks by cars and had penetrated the concrete surface. In addition, , de-icing salt had been routinely spread on the roof decks to prevent ponding water from freezing.

\subsection{Galvanic anodes}

The design for the structural repairs involved removing only physically deteriorated concrete by jack hammer. The breakouts extended beyond the back of the reinforcement to minimum additional depth equal to the aggregate size of the repair mortar plus $3 \mathrm{~mm}$. The steel was cleaned by means of rotary steel wire brushes (Christodoulou et al. 2013).

The nature of commercial contracts and their risk allocation typically require that a contractor uses specialist repair materials conforming to a standard. For the restoration of the concrete profile a class R3 structural repair mortar in accordance to BS EN 1504-3 was applied (Concrete Society 2009, BSI 2005). The repair materials was a Portland cement based flowable, polymer modified, shrinkage compensated micro-concrete, which is poured and trowel finished.
Table 1. Summary of anode types, installation location and properties.

\begin{tabular}{|c|c|c|}
\hline $\begin{array}{l}\text { Anode } \\
\text { type }\end{array}$ & $\begin{array}{l}\text { Installation } \\
\text { location }\end{array}$ & Properties \\
\hline A & $\begin{array}{l}\text { Parent con- } \\
\text { crete }\end{array}$ & $\begin{array}{l}\text { Cylindrically shaped, di- } \\
\text { ameter } 20 \mathrm{~mm} \text {, length } 40 \mathrm{~mm} \text {, } \\
65 \text { grams of zinc, coated } \\
\text { with activator }\end{array}$ \\
\hline B & Patch repair & $\begin{array}{c}\text { Circularly shaped, diame- } \\
\text { ter } 65 \mathrm{~mm} \text {, thickness } 30 \mathrm{~mm} \text {, } \\
60 \text { grams of zinc, encapsu- } \\
\text { lated in activator }\end{array}$ \\
\hline
\end{tabular}

Anodes type A, were installed in pre-drilled holes of $25 \mathrm{~mm}$ diameter and $45 \mathrm{~mm}$ long in the parent concrete, as close as practically possible to the edge of the patch and then filled with proprietary backfill (Figure 2). A titanium wire integrated with the galvanic anodes made a connection to the steel reinforcement within the repair area. Their installation spacing was $250 \mathrm{~mm}$ centres.

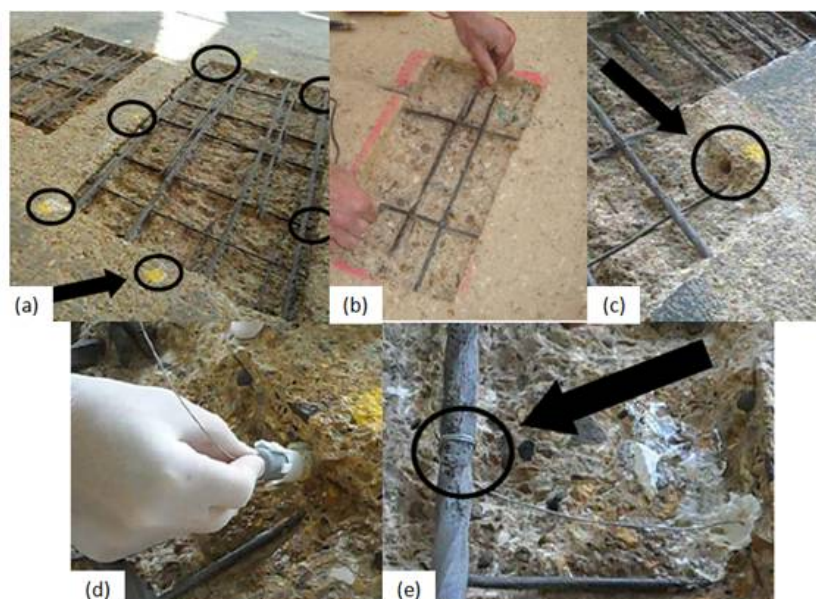

Figure 2. Galvanic anode type A installation procedure, (a) repair area following breakout and with location of anode installation marked out, (b) testing for reinforcement continuity, (c) pre-drilled holes for anode installation, (d) installation of galvanic anode and (e) connection of galvanic anode to the steel reinforcement and anode hole following filling with the proprietary backfill (Christodoulou et al. 2014)

Anodes type B were installed within the patch repair on the side of the exposed reinforcement, as closely as possible to the edge of the repair. A steel wire integrated with the galvanic anodes made a connection to the steel reinforcement. The anodes were also encapsulated in a proprietary embedment mortar to provide a conductive path to the substrate (Figure 3). Their installation spacing was $250 \mathrm{~mm}$ centres. 


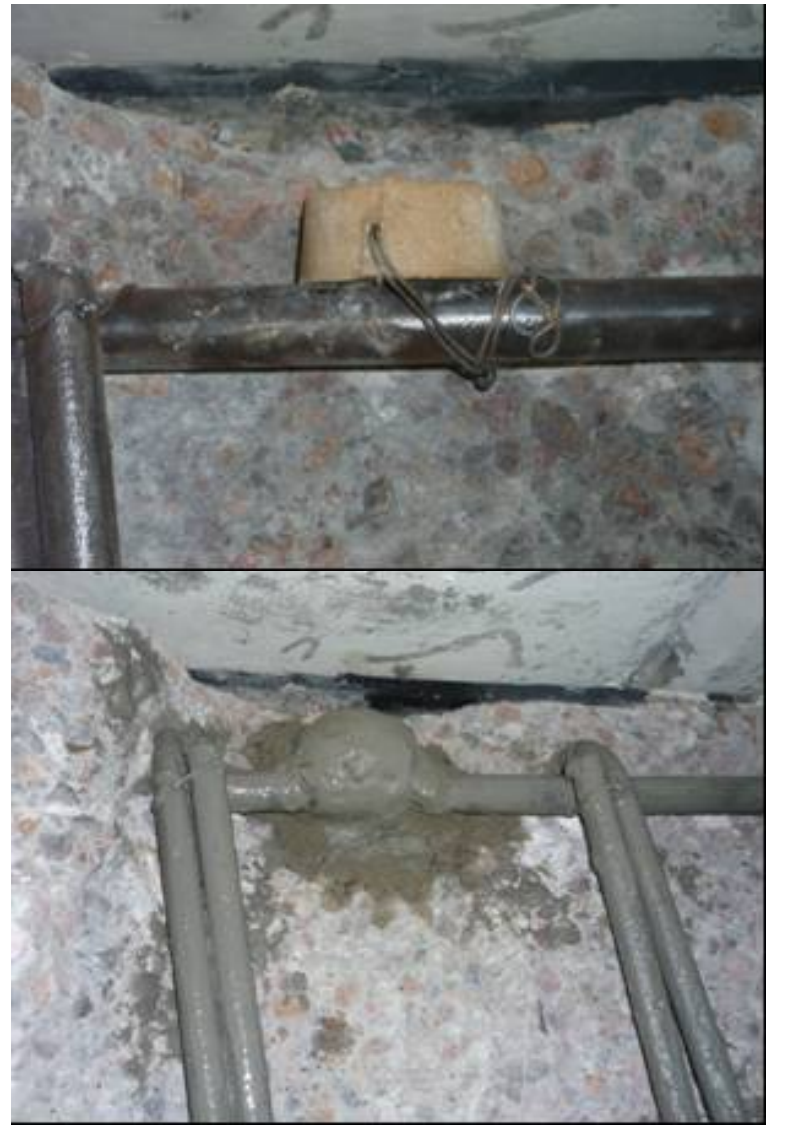

Figure 3. Galvanic anode type B installation procedure, (left) anode tied to the reinforcement as close as practically possible to the edge of the repair and (right) galvanic anode encapsulated in proprietary embedment mortar.

\subsection{Testing regime}

Measuring steel potentials against the potential of a standard reference electrode (i.e. absolute potentials) is a well established non-destructive monitoring technique (Elsener 2001, Elsener 2003, Concrete Society 2004, ASTM 2009). An alternative to this, are electrode to electrode potentials (i.e. relative potentials) which provide information on the electric field in concrete and as such locating areas of actively corroding steel by considering spatial variation of potentials (Elsener 2003, Glass et al. 2010).

Potential maps were obtained on a $50 \mathrm{~mm}$ square grid using a portable $\mathrm{Ag} / \mathrm{AgCl} / 0.5 \mathrm{M} \mathrm{KCl}$ reference electrode and a high impedance multi-meter. The size of each grid varied in accordance to the size of the repair but in general it extended up to $700 \mathrm{~mm}$ in the parent concrete when measured from the edge of the repair. All the potential values herein are reported relative to the most positive value obtained at the time of the measurement.

\section{RESULTS}

The following sections provide a summary of the results for anode types A and B.

\subsection{Anode Type A}

The typical polarisation effect afforded by anodes type $\mathrm{A}$ at a distance away from the edge of the patch repair between 110 and 215 days following installation is shown in Figure 4. It can be observed that the anodes affected the potentials to a distance of approximately $600 \mathrm{~mm}$ from the edge of the repair even after 215 days. The time dependant trends observed can be attributed to changes in the weather conditions.

Figure 5 demonstrates the results of potential mapping around the perimeter of a patch repair with anode type A over a period of 195 days. It can be observed that the anodic points identified in the mapping, coincided at all times with the location of the galvanic anodes (anodic points have been circled). It can be observed that the potentials never rose higher than the imaginary lines connecting the anodic spots, suggesting that there are no other anodic spots between the galvanic anodes.

These results were typical and re-occurring findings through all the patch repairs on this MSCP for the polarisation effect afforded by galvanic anodes type A to steel in parent concrete at a distance from the edge of the patch repair. Readings past 215 days could unfortunately not be obtained, as thereafter the slabs received a surface applied waterproofing coating.

\subsection{Anode Type B}

The typical polarisation effect afforded by anodes type $\mathrm{B}$ at a distance away from the edge of the patch repair over a period of 28 days following installation is shown in Figure 6. It can be observed that there was a polarisation effect almost over the entire measurement length of $800 \mathrm{~mm}$ over the first 15 days. However, at 28 days it was observed that the effect was entirely lost and no polarisation was afforded to the steel in the parent concrete adjacent to the repair.

In a similar repair with type B anodes, potential mapping over a period of 28 days demonstrated that the anodes provided no polarisation effect at all to the reinforcement in the parent concrete adjacent to the patch repair (Figure 7). Unlike the previous repair, this behaviour was experienced from day 2 and throughout the testing. The above, are typical and re-occurring findings for the polarisation effect afforded by galvanic anodes type B to steel in parent concrete at a distance from the edge of the patch repair. Readings over 28 days could not be obtained, as thereafter the local concrete patch repairs received a surface applied waterproofing coating 


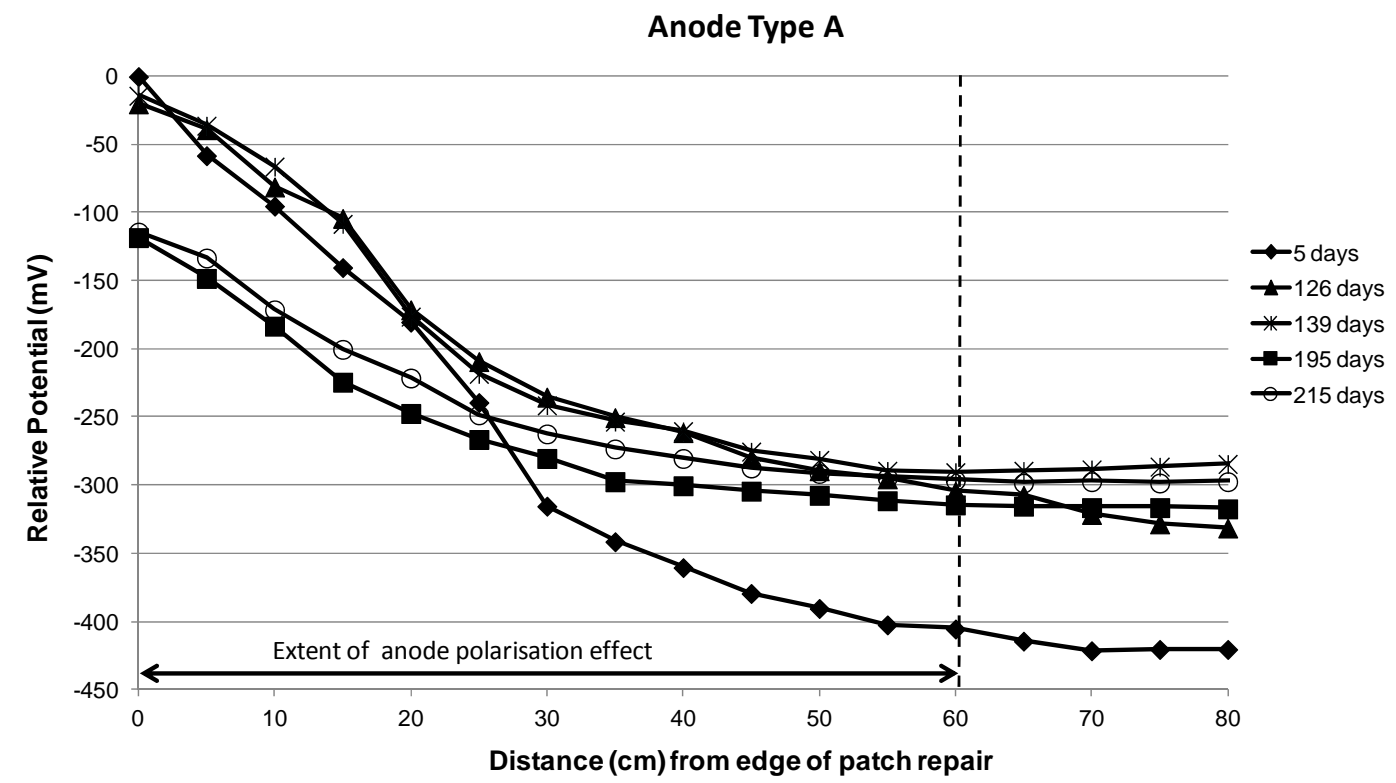

Figure 4. Polarisation effect afforded by anodes type A at a distance from the edge of a patch repair over a period of 215 days.

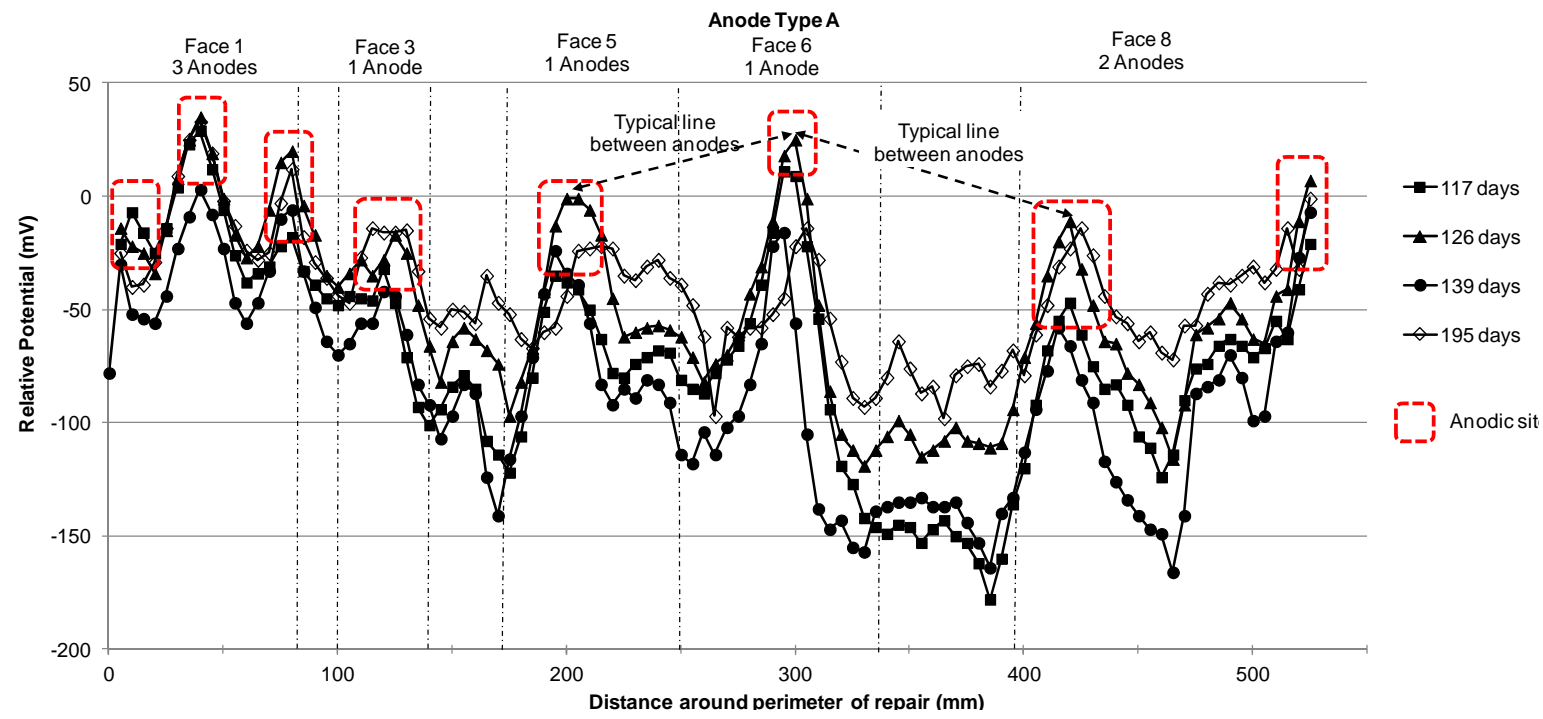

Figure 5. Potential mapping around a patch repair location with anodes type A over a period of 195 days

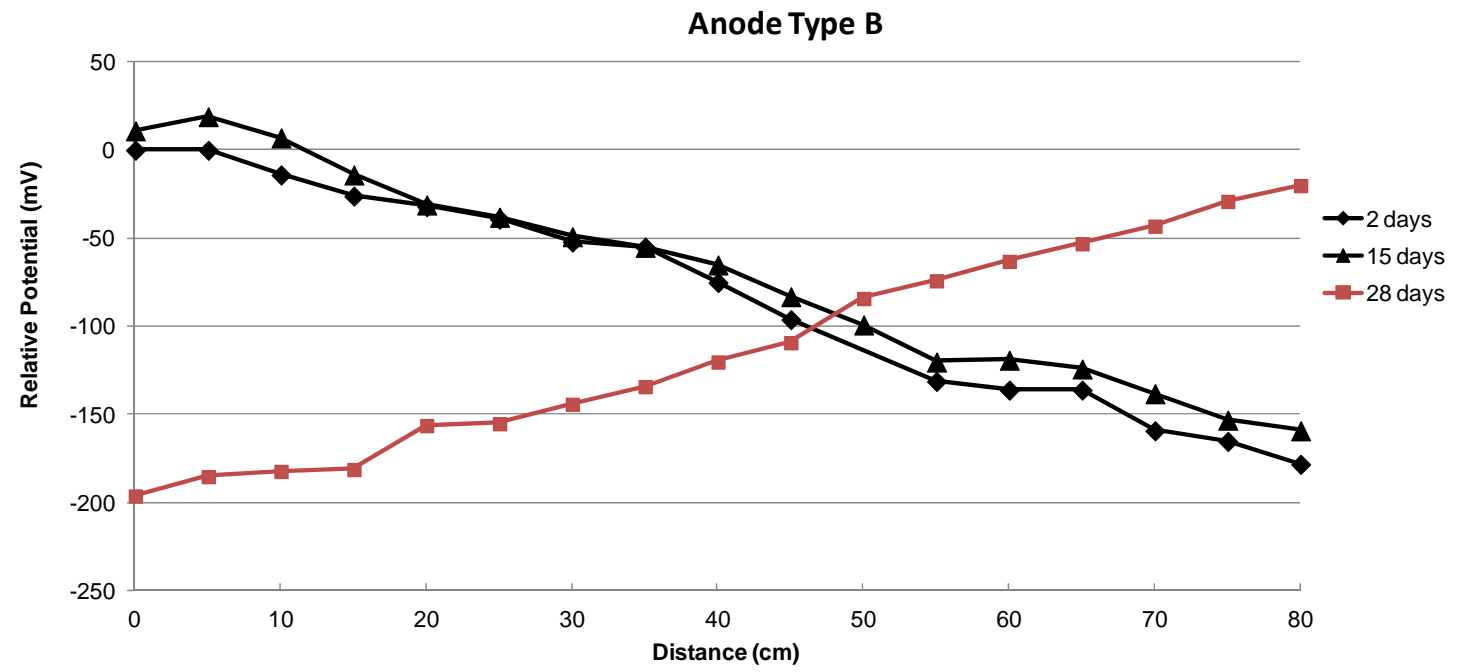

Figure 6. Polarisation effect afforded by anodes type B at a distance from the edge of a patch repair over a period of 28 days. 
Anode Type B

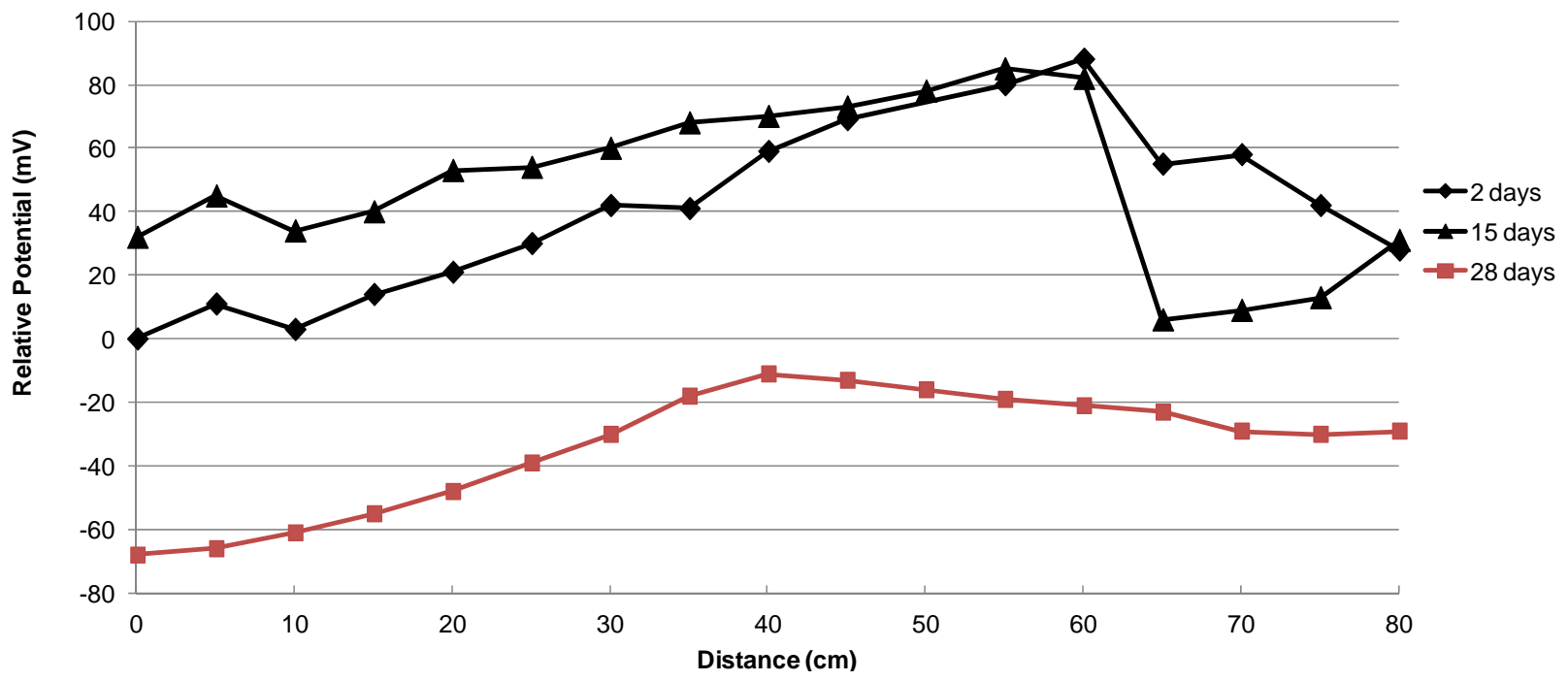

Figure 7. Polarisation effect afforded by anodes type B at a distance from the edge of a patch repair over a period of 28 days.

\section{DISCUSSION}

This study investigated the performance of two different types of galvanic anodes installed both in the parent concrete and the patch repair material itself. Monitoring was performed by close-interval relative potential mapping around the perimeter of the repairs to verify that the anodes were still active, and at staged distances away from the repairs to assess the polarisation effect afforded by the anodes to the steel in the parent concrete.

The monitoring data indicated a variance in the performance between anode types A and B. Galvanic anodes type $\mathrm{A}$, installed in the parent concrete around the repair, demonstrated polarisation effects of up to $600 \mathrm{~mm}$ away from the patch repair itself over a period of 215 days. However galvanic anodes type $\mathrm{B}$, embedded within the patch repair itself, demonstrated limited polarisation effects and in cases none at all over a period of 28 days. Similar observations have also been made by Dugarte and Sagues (2007).

These above observations suggest that the choice of repair material may have an influence in the performance of galvanic anodes. In this particular case, the repair material was a structural repair mortar class R3 in accordance to BS EN 1507 (British Standards Institution 2005). As such, consideration should be given in the compatibility between galvanic anodes and repair material. It is considered appropriate that materials conforming to the requirements of BS EN 1507 (BSI 2005) are used at all times for concrete repairs and the installation of galvanic anodes is amended to suit. An opposite approach, would result in the use of non-conforming repair materials and increase the risk for failure of the concrete repair.
Traditionally, half-cell potential mapping in the UK is undertaken based on a $500 \mathrm{~mm}$ grid and for rapid corrosion assessment spacing up to $1.2 \mathrm{~m}$ is occasionally employed (ASTM 2009). Undertaking relative potential mapping at a small grid $(50 \mathrm{~mm})$, as in the case of this study, has the advantage of collecting time-dependent spatial variation information regarding the condition of the reinforcement. This is particularly suited to galvanic systems which are often installed without any monitoring facility (including a connection to the steel reinforcement).

A new criterion to that of $100 \mathrm{mV}$ depolarisation (BSI 2012), may be adopted for assessing the performance of galvanic anode systems by means of potential mapping to obtain spatial variations. Potential mapping around the perimeter of a patch repair with galvanic anodes installed in the parent concrete, should demonstrate that the anodes afford a dominant (i.e. be dominant over any effect of a steel anode) influence on the steel potentials away from the area of the patch repair that is at least equal to half the spacing between anodes. This alternative performance criterion is also in line with the work of Holmes et al (2011).

\section{CONCLUSIONS}

The results of this work lead to the following conclusions:

- Galvanic anodes type A, installed in pre-drilled cavities formed in the parent concrete exposed within an area of patch repair, can provide substantially higher levels of polarisation to the steel reinforcement in the parent concrete outside the repair compared to galvanic anodes embedded directly within the patch repair itself (type B). Type 
A, had a dominant effect on potentials within the concrete to a distance of approximately $600 \mathrm{~mm}$ from the edge of the patch repair over a period of 215 days, type $B$ the latter had no influence after 28 days.

- A repair material that conforms to standards for structural repairs such as BS EN 1504 (BSI 2005) can significantly affect the performance of galvanic anodes type B (within the patch repair), whereas it had no effect on the performance of galvanic anodes type A.

- Close-interval potential mapping (50mm spacing) is an effective technique to assess the performance of galvanic anodes. It has the additional advantage that localised active corrosion spots can also be detected if present.

- An alternative criterion, to that of $100 \mathrm{mV}$ depolarisation, is proposed for assessing the performance of galvanic anodes: the anodes should afford a dominant (i.e. be dominant over any effect of a steel anode) influence on the steel potentials away from the area of patch repair that is at least equal to half the spacing between anodes.

\section{REFERENCES}

American Society for Testing and Materials, 2009. ASTM C 876 - 2009, Standard Test Method for Corrosion Potentials of Uncoated Reinforcing Steel in Concrete, West Conshohocken, Pennsylvania, USA.

British Standards Institution, BS EN ISO 12696:2012, Cathodic protection of steel in concrete, London: BSI, 2012.

British Standards Institution, BS EN 1504:2005 Products and Systems for the Protection and Repair of Concrete Structures - Definitions, Requirements, Quality Control and Evaluation of Conformity - Part 3: Structural and Non Structural Repair, BSI, London, 2005.

Christodoulou C., Electrochemical treatments of corroded reinforcement in concrete. IN: Alexander, $M$. et al. (eds.)Concrete Repair, Rehabilitation and Retrofitting II Proceedings of the 2nd International Conference on Concrete Repair, Rehabilitation and Retrofitting, ICCRRR-2, 24-26 November 2008, Cape Town, South Africa, pp. 297 - 298, ISBN 978-0-415-46850-3

Christodoulou, C., Glass, G., Webb, J. 2009. Corrosion management of concrete structures, The Structural Engineer, Volume 87, 23/24, December 2009.

Christodoulou C., Glass G., Webb J., Austin S.A. Goodier C.I., A new approach for the patch repair of car parks using galvanic anodes, Concrete Solutions 2011, : Grantham, M., Mechtcherine, V. and Schneck, U. (eds). Concrete Solutions 2011: Proceedings of the $4^{\text {th }}$ nternational Conference on Concrete Repair 2011. London: CRC Press, ISBN 9780-203-13468-9.

Christodoulou C., Goodier C.I., Austin S.A, Webb J., Glass G., Diagnosing the cause of incipient anodes in repaired reinforced concrete structures, Corrosion Science, 69 (2013), pp. $123 \quad-\quad 129 \quad$ DOI information: 10.1016/j.corsci.2012.11.032
Christodoulou C, Goodier C, Austin S, Webb J, Glass G, A new arrangement of galvanic anodes for the repair of reinforced concrete structures, Construction and Building Materials, 50 (2014), pp. 300 - 307, DOI information: 10.1016/j.conbuildmat.2013.09.062

Concrete Society 2004, Technical Report 60, Electrochemical tests for reinforcement corrosion, Surrey, UK.

Concrete Society 2009, Repair of concrete structures with reference to BS EN 1504, Technical Report 69, Surrey, UK.

Concrete Society 2011, Technical Report 73, Cathodic Protection of Steel in Concrete, Surrey, UK.

Design Manual for Road and Bridges, Volume 3, Section 3, Part BA 35/1990 Inspection and Repair of Concrete Highway Structures, Departmental Standard, UK.

Dugarte M., Sagüés A.A., Galvanic point anodes for extending the service life of patched areas upon reinforced concrete bridge members, Contract No. BD544-09, Final Report to Florida Department of Transportation, Tampa, Florida, USA, September 2009.

Elsener B. 2001. Half-cell potential mapping to assess repair work on RC structures, Construction and Building Materials, 15, $133-139$.

Elsener B. 2003, Half cell potential measurements-potential mapping on reinforced concrete structures, RILEM TC 154-EMC: electrochemical techniques for measuring metallic corrosion, Mater. Struct. 36, pp. 461-471.

Glass G., Christodoulou C., Holmes S.P., 2012, Protection of steel in concrete using galvanic and hybrid electrochemical treatments, IN: Alexander, M.G. et al. (eds.), Concrete Repair, Rehabilitation and Retrofitting III - Proceedings of the 3rd International Conference on Concrete Repair, Rehabilitation and Retrofitting, ICCRRR 2012, pp. 523 - 526, ISBN 978-0-415-89952-9.

Glass G.K., Davison N., Roberts A.C. 2010, Monitoring Method, UK Patent GB 2449039 B.

John G., Cottis B., Laboratory Testing and Computer Modelling of the Performance of Sacrificial Anodes for use in Reinforced Concrete Structures, Paper number 03302, Corrosion 2003, NACE International, Houston, USA.

Holmes S.P., Wilcox G.D., Robins P.J., Glass G.K., Roberts A.C., Responsive behaviour of galvanic anodes in concrete and the basis for its utilisation, Corrosion Science, 53 (2011), pp. 3450 - 3454.

NACE International Publication 01105, Item No. 24224, Sacrificial Cathodic protection of Reinforced Concrete Elements - A State-of-the-Art Report, Houston, USA, March 2005 